Kong Mun Lo, See Mun Lee and Edward R.T. Tiekink*

\title{
Crystal structure of $4,4^{\prime}$-(oxybis(methylene))bis (bromobenzene), $\mathrm{C}_{14} \mathrm{H}_{12} \mathrm{Br}_{2} \mathrm{O}$
}

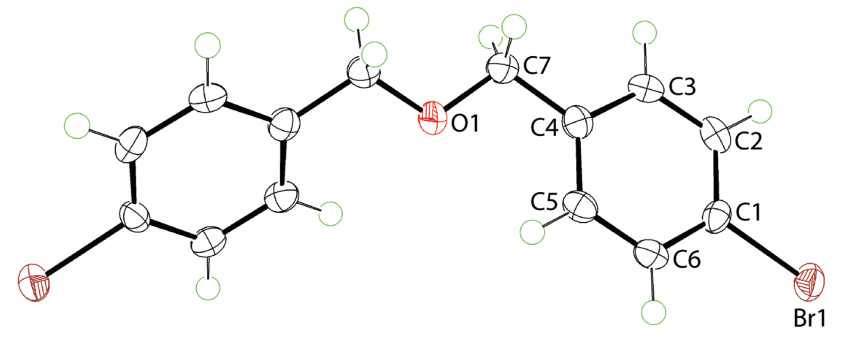

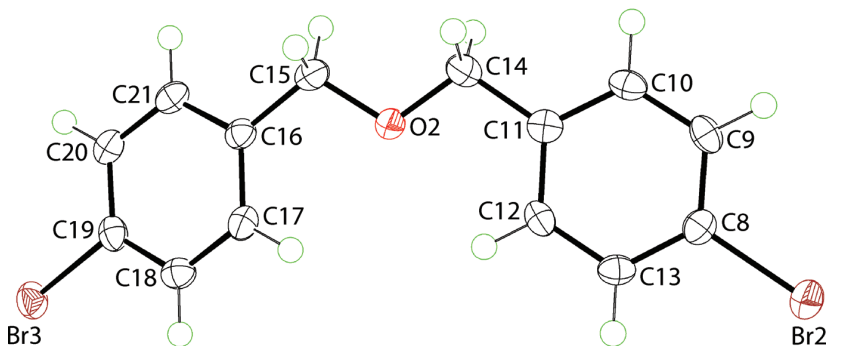

https://doi.org/10.1515/ncrs-2020-0280

Received June 10, 2020; accepted June 25, 2020; available online July 10, 2020

\section{Abstract}

$\mathrm{C}_{14} \mathrm{H}_{12} \mathrm{Br}_{2} \mathrm{O}, \quad$ monoclinic, $C 2$ (no. 5), $a=29.7356(3) \AA$, $b=5.88712(4) \AA, \quad c=11.10915(9) \AA, \quad \beta=99.1700(8)^{\circ}$, $V=1919.88(3) \AA^{3}, Z=6, R_{\mathrm{gt}}(F)=0.0166, w R_{\text {ref }}\left(F^{2}\right)=0.0443$, $T=100(2) \mathrm{K}$.

\section{CCDC no.: 2012231}

Table 1 contains crystallographic data and Table 2 contains the list of the atoms including atomic coordinates and displacement parameters.

\section{Source of material}

Di(4-bromobenzyl)tin dibromide was synthesised by the direct reaction of 4-bromobenzyl bromide (Merck) and

\footnotetext{
*Corresponding author: Edward R.T. Tiekink, Research Centre for Crystalline Materials, School of Science and Technology, Sunway University, 47500 Bandar Sunway, Selangor Darul Ehsan, Malaysia, e-mail: edwardt@sunway.edu.my. https://orcid.org/0000-00031401-1520

Kong Mun Lo and See Mun Lee: Research Centre for Crystalline Materials, School of Science and Technology, Sunway University, 47500 Bandar Sunway, Selangor Darul Ehsan, Malaysia
}

Table 1: Data collection and handling.

\begin{tabular}{|c|c|}
\hline Crystal: & Colourless prism \\
\hline Size: & $0.14 \times 0.08 \times 0.04 \mathrm{~mm}$ \\
\hline Wavelength: & $\mathrm{Cu} K \alpha$ radiation $(1.54184 \AA$ ) \\
\hline$\mu:$ & $7.87 \mathrm{~mm}^{-1}$ \\
\hline Diffractometer, scan mode: & XtaLAB Synergy, $\omega$ \\
\hline$\theta_{\max }$, completeness: & $67.1^{\circ},>99 \%$ \\
\hline$N(h k l)_{\text {measured }}, N(h k l)_{\text {unique }}, R_{\text {int }}:$ & $22804,3289,0.029$ \\
\hline Criterion for $I_{\mathrm{obs}}, N\left(h k l_{\mathrm{gt}}\right.$ : & $I_{\text {obs }}>2 \sigma\left(I_{\text {obs }}\right), 3270$ \\
\hline$N(\text { param })_{\text {refined }}:$ & 231 \\
\hline Programs: & $\begin{array}{l}\text { CrysAlis }{ }^{\text {PRO }}[1] \text {, SHELX }[2,3] \text {, } \\
\text { WinGX/ORTEP [4] }\end{array}$ \\
\hline
\end{tabular}

Table 2: Fractional atomic coordinates and isotropic or equivalent isotropic displacement parameters $\left(\AA^{2}\right)$.

\begin{tabular}{lrrrr}
\hline Atom & $\boldsymbol{x}$ & $\boldsymbol{y}$ & $\boldsymbol{z}$ & $\boldsymbol{U}_{\text {iso }}{ }^{*} \boldsymbol{U}_{\text {eq }}$ \\
\hline Br1 & $0.71041(2)$ & $1.07282(6)$ & $0.49566(3)$ & $0.02286(10)$ \\
O1 & 0.500000 & $0.6195(6)$ & 0.500000 & $0.0243(8)$ \\
C1 & $0.65770(10)$ & $0.8905(6)$ & $0.5020(3)$ & $0.0171(7)$ \\
C2 & $0.66291(11)$ & $0.6783(6)$ & $0.5555(3)$ & $0.0190(7)$ \\
H2 & 0.692322 & 0.620597 & 0.586411 & $0.023^{*}$ \\
C3 & $0.62408(10)$ & $0.5515(6)$ & $0.5630(3)$ & $0.0179(6)$ \\
H3 & 0.627095 & 0.405373 & 0.599724 & $0.021^{*}$ \\
C4 & $0.58078(11)$ & $0.6342(6)$ & $0.5177(3)$ & $0.0172(7)$ \\
C5 & $0.57695(11)$ & $0.8488(6)$ & $0.4634(3)$ & $0.0179(7)$ \\
H5 & 0.547658 & 0.907569 & 0.432146 & $0.021^{*}$ \\
C6 & $0.61544(10)$ & $0.9773(6)$ & $0.4546(3)$ & $0.0180(7)$ \\
H6 & 0.612751 & 1.122309 & 0.416662 & $0.022^{*}$ \\
C7 & $0.53983(10)$ & $0.4892(6)$ & $0.5253(3)$ & $0.0188(7)$ \\
H7A & 0.538544 & 0.362960 & 0.465956 & $0.023^{*}$ \\
H7B & 0.542269 & 0.423023 & 0.607969 & $0.023^{*}$ \\
Br2 & $0.52995(2)$ & $-0.04917(6)$ & $0.79106(3)$ & $0.02331(10)$ \\
Br3 & $0.94938(2)$ & $-0.07311(5)$ & $0.80258(3)$ & $0.02156(9)$ \\
O2 & $0.74410(7)$ & $0.3942(4)$ & $0.8522(2)$ & $0.0202(5)$ \\
C8 & $0.58424(10)$ & $0.1270(6)$ & $0.8185(3)$ & $0.0167(7)$ \\
C9 & $0.58410(10)$ & $0.3387(6)$ & $0.8726(3)$ & $0.0173(6)$ \\
H9 & 0.556937 & 0.398759 & 0.894875 & $0.021^{*}$ \\
C10 & $0.62434(10)$ & $0.4612(6)$ & $0.8936(3)$ & $0.0170(6)$ \\
H10 & 0.624690 & 0.606480 & 0.930955 & $0.020^{*}$ \\
C11 & $0.66434(11)$ & $0.3752(5)$ & $0.8607(3)$ & $0.0157(6)$ \\
C12 & $0.66356(11)$ & $0.1620(6)$ & $0.8063(3)$ & $0.0163(6)$ \\
H12 & 0.690670 & 0.101474 & 0.783930 & $0.020^{*}$ \\
C13 & $0.62348(10)$ & $0.0368(6)$ & $0.7844(3)$ & $0.0167(6)$ \\
H13 & 0.622936 & -0.108207 & 0.746686 & $0.020^{*}$ \\
C14 & $0.70685(11)$ & $0.5178(6)$ & $0.8814(3)$ & $0.0193(7)$ \\
& & & &
\end{tabular}


Table 2 (continued)

\begin{tabular}{lrrrr}
\hline Atom & $\boldsymbol{x}$ & $\boldsymbol{y}$ & $\boldsymbol{z}$ & \multicolumn{1}{c}{$\boldsymbol{U}_{\text {iso }}{ }^{*} \boldsymbol{U}_{\text {eq }}$} \\
\hline H14A & 0.702225 & 0.655973 & 0.830156 & $0.023^{*}$ \\
H14B & 0.713253 & 0.565810 & 0.967851 & $0.023^{*}$ \\
C15 & $0.78371(10)$ & $0.5299(6)$ & $0.8572(3)$ & $0.0195(7)$ \\
H15A & 0.790202 & 0.607906 & 0.937059 & $0.023^{*}$ \\
H15B & 0.778801 & 0.647046 & 0.792493 & $0.023^{*}$ \\
C16 & $0.82363(10)$ & $0.3810(5)$ & $0.8398(3)$ & $0.0155(7)$ \\
C17 & $0.81764(11)$ & $0.1725(6)$ & $0.7811(3)$ & $0.0172(6)$ \\
H17 & 0.787784 & 0.121274 & 0.749548 & $0.021^{*}$ \\
C18 & $0.85501(10)$ & $0.0381(6)$ & $0.7680(3)$ & $0.0177(6)$ \\
H18 & 0.850948 & -0.105026 & 0.728238 & $0.021^{*}$ \\
C19 & $0.89837(10)$ & $0.1166(6)$ & $0.8141(3)$ & $0.0170(7)$ \\
C20 & $0.90519(10)$ & $0.3266(6)$ & $0.8701(3)$ & $0.0178(6)$ \\
H20 & 0.935093 & 0.380005 & 0.899128 & $0.021^{*}$ \\
C21 & $0.86749(10)$ & $0.4572(6)$ & $0.8828(3)$ & $0.0180(6)$ \\
H21 & 0.871680 & 0.601102 & 0.921646 & $0.022^{*}$ \\
\hline
\end{tabular}

metallic tin powder (Merck) in toluene according to a literature procedure [5]. The prepared organotin compound was recrystallized in dimethyl sulfoxide together with few drops of water. The title compound was obtained as side-product from the recrystallisation process.

Yield: $0.05 \mathrm{~g}$ (14.0\%). M.pt (Mel-temp II digital melting point apparatus): 450-452 K. IR (Bruker Vertex 70v FTIR Spectrophotometer; $\mathrm{cm}^{-1}$ ): 1470 (m) v(CC), 1034 (m) v(CO). ${ }^{1} \mathbf{H}$ NMR (Bruker Ascend $400 \mathrm{MHz}$ NMR spectrometer, chemical shifts relative to $\mathrm{Me}_{4} \mathrm{Si}$, DMSO- $d_{6}$ solution; ppm): 3.38 (s, 4H, $\mathrm{CH}_{2}$ ), 7.11-7.28 (m, 4H, Ph-H), 7.33-7.50 (m, 4H, Ph-H). ${ }^{13} \mathbf{C}\left\{{ }^{1} \mathbf{H}\right\}$ NMR (as for ${ }^{1} \mathrm{H}$ NMR): $40.6\left(\mathrm{CH}_{2}\right), 127.1,127.8,129.9$, $130.3(\mathrm{Ph}-\mathrm{C})$.

\section{Experimental details}

The hydrogen atoms were geometrically placed $(\mathrm{C}-\mathrm{H}=0.95-$ $0.99 \AA$ A) and refined as riding with $U_{\text {iso }}(\mathrm{H})=1.2 U_{\text {eq }}(\mathrm{C})$. The absolute structure was determined based on differences in Friedel pairs included in the data set (Flack-Parsons parameter: 0.000(12) using 1382 quotients). The maximum and minimum residual electron density peaks of 0.62 and 0.25 e $\AA^{-3}$, respectively, were located 0.95 and $0.61 \AA$ from the $\mathrm{H} 7 \mathrm{~b}$ and $\mathrm{Br} 1$ atoms, respectively.

\section{Comment}

For a rather simple composition, crystal structure determinations of dibenzylether molecules with the general formula $\mathrm{ArCH}_{2} \mathrm{OCH}_{2} \mathrm{Ar}$ are comparatively rare. The structure of the parent compound, $\mathrm{PhCH}_{2} \mathrm{OCH}_{2} \mathrm{Ph}$ is known [6], as are symmetric 2,2'- $\mathrm{Br}_{2}[7], 2,2^{\prime}-\mathrm{I}_{2}[8], 3,3^{\prime}-\left(\mathrm{NO}_{2}\right)_{2}[9], 4,4^{\prime}-(\mathrm{CN})_{2}[10]$ and $3,4,3^{\prime}, 4^{\prime}-(\mathrm{OMe})_{4}$ [11] derivatives. Herein, the crystal and molecular structures of $4-\mathrm{BrPhCH}_{2} \mathrm{OCH}_{2} \mathrm{PhBr}-4$ (I) are described.
Compound (I) became available as a side-product as detailed in the "Source of material".

The crystallographic asymmetric unit of (I) comprises one-half molecule, being disposed about a 2-fold axis with the $\mathrm{O}$ atom lying on the axis, and a full molecule in a general position. The molecular structures in (I) are shown in the figure (70\% displacement ellipsoids; unlabelled atoms for the Br1containing molecule are related by the symmetry operation $1-x, y, 1-z)$. The molecules, in common with the literature precedents, feature a central $O$ atom connected on either side by benzyl/substituted benzyl substituents. However, nontrivial conformational differences are apparent, specifically in the relative disposition of the aryl substituents. For the 2-fold symmetric molecule in (I), the dihedral angle between the aryl rings is $48.94(9)^{\circ}$, which compares to $15.96(10)^{\circ}$ for the non-symmetric molecule. The other obvious difference between the molecules relates to the $\mathrm{C}_{\text {ring }}-\mathrm{C}_{\text {methylene }}-\mathrm{O}-$ $\mathrm{C}_{\text {methylene }}$ torsion angles which are $2 \times 164.7(3)^{\circ}$ for the Br1molecules, and 173.3(3) and 173.4(3) ̊ for the Br2-molecule. The aforementioned parameters lie within the ranges of comparable values in the literature structures. Thus, the dihedral angle between rings in the $2,2^{\prime}-\mathrm{Br}_{2}[7]$ derivative is a small $3.1^{\circ}$ and the widest dihedral angle of $57.38(7)^{\circ}$ is found in the $4,4^{\prime}-(\mathrm{CN})_{2}$ [10] derivative. The greatest difference in the $\mathrm{C}_{\text {ring }}-\mathrm{C}_{\text {methylene }}-\mathrm{O}-\mathrm{C}_{\text {methylene }}$ torsion angles, indicating the largest twist in the central residue is found in the $3,4,3^{\prime}, 4^{\prime}$ $(\mathrm{OMe})_{4}[11]$ species, i.e. $73.27(18)$ and $177.42(14)^{\circ}$. In all of the other structures, the differences in these torsion angles is less than $10^{\circ}$.

In the crystal of (I), weak non-covalent $\pi \cdots \pi$ stacking $\left[\mathrm{Cg}(\mathrm{C} 1-\mathrm{C} 6) \cdots \mathrm{Cg}(\mathrm{C} 16-\mathrm{C} 21)^{\mathrm{i}}=3.8582(19) \AA\right.$ A , angle of inclination $=1.51(16)^{\circ}$ for symmetry operation (i) $3 / 2-x, 1 / 2+y$, $1-z]$ and four independent phenyl- $\mathrm{C}-\mathrm{H} \cdots \pi$ (phenyl) [shortest contact: $\mathrm{C} 13-\mathrm{H} 13 \cdots \mathrm{Cg}(\mathrm{C} 1-\mathrm{C} 6)^{\mathrm{ii}}=2.73$ Å with angle at $\mathrm{H} 13=132^{\circ}$ for (ii) $\left.x,-1+y, z\right]$ combine to assemble molecules into a three-dimensional architecture.

A further analysis of the molecular packing scheme was conducted by calculating the Hirshfeld surfaces and two-dimensional fingerprint plots (overall and decomposed) employing Crystal Explorer 17 [12] using standard protocols [13]. First and foremost, the calculations indicated distinct percentage contributions for the two independent molecules comprising the asymmetric unit [13]. As anticipated from the description of the molecular packing, significant contributions to the surface contacts revealed the dominance of $\mathrm{H} \cdots \mathrm{H}=31.6 \%$ [31.9\% for the Br2-molecule] and $\mathrm{C} \cdots \mathrm{H} / \mathrm{H} \cdots \mathrm{C}=21.3 \%$ [27.1\%]. Very significant contributions are also made by $\mathrm{Br} \cdots \mathrm{H} / \mathrm{H} \cdots \mathrm{Br}$ contacts, i.e. 35.6 and $31.7 \%$, respectively, but at separations longer than the sum of the van der Waals radii. The same is true of $\mathrm{Br} \cdots \mathrm{Br}$ contacts [2.9 and 2.6\%]. Other notable contacts are $\mathrm{Br} \cdots \mathrm{C} / \mathrm{C} \cdots \mathrm{Br}$ 
[1.6 and $0.8 \%$ ], $\mathrm{Br} \cdots \mathrm{O} / \mathrm{O} \cdots \mathrm{Br}[1.1$ and $0.5 \%$ ], $\mathrm{O} \cdots \mathrm{H} / \mathrm{H} \cdots \mathrm{O}$ [0.6 and 2.6\%] and C... [ [5.4 and 2.7\%].

Acknowledgements: Sunway University Sdn Bhd is thanked for financial support of this work through Grant No. STRRCTR-RCCM-001-2019.

\section{References}

1. Rigaku Oxford Diffraction: CrysAlis ${ }^{\mathrm{PRO}}$. Rigaku Corporation, Oxford, UK (2018).

2. Sheldrick, G. M.: A short history of SHELX. Acta Crystallogr. A64 (2008) 112-122.

3. Sheldrick, G. M.: Crystal structure refinement with SHELXL. Acta Crystallogr. C71 (2015) 3-8.

4. Farrugia, L. J.: WinGX and ORTEP for Windows: an update. J. Appl. Crystallogr. 45 (2012) 849-854.

5. Sisido, K.; Takeda, Y.; Kinugawa, Z.: Direct synthesis of organotin compounds I. di- and tribenzyltin chlorides. J. Am. Chem. Soc. 83 (1961) 538-541.

6. Nefedov, S. E.; Uvarova, M. A.; Golubichnaya, M. A.; Nefedova, I. V.; Chikhichin, D. G.; Kotseruba, V. A.; Levchenko, O. A.; Kamalov, G. L.: A hexanuclear cobalt(III) complex containing the pseudocubane fragment $\left[\mathrm{CO}_{4}\left(\mu_{4}-0\right)_{2}\left(\mu_{3}-0\right)_{2}\right]$ in its metal framework and a solvated dibenzyl ether molecule. Russ. J. Coord. Chem. 40 (2014) 358-365.

7. Berndt, A. F.; Corey, E. R.; Glick, M. D.: o,o'-Dibromodibenzyl ether. Acta Crystallogr. B37 (1981) 1294-1296.

8. Hashmi, S. K. A.; Schafer, S.; Fischer, P.; Gil, C. D.; Bats, J. W.: Private Communication to the Cambridge Structural Database. Refcode HACMEG, The Cambridge Structural Database, England (2014).

9. Jones, P. G.: Bis( $m$-nitrobenzyl) ether. Acta Crystallogr. C43 (1987) 364-366.

10. Xiao, J.; Zhao, H.: 4,4'-(Oxydimethylene)dibenzonitrile. Acta Crystallogr. E64 (2008) 01436.

11. Fun, H. K.; Chinnakali, K.; Sivakumar, K.; Sam, T.-W.; How, S.-E.: Bis(3,4-dimethoxybenzyl) ether and tetramethoxy4,4'-(2,3-dimethyltetramethylene)dipyrocatechol. Acta Crystallogr. C53 (1997) 1857-1859.

12. Turner, M. J.; Mckinnon, J. J.; Wolff, S. K.; Grimwood, D. J.; Spackman, P. R.; Jayatilaka, D.; Spackman, M. A.: Crystal Explorer v17. The University of Western Australia, Australia (2017).

13. Tan, S. L.; Jotani, M. M.; Tiekink, E. R. T.: Utilizing Hirshfeld surface calculations, non-covalent interaction $(\mathrm{NCl})$ plots and the calculation of interaction energies in the analysis of molecular packing. Acta Crystallogr. E75 (2019) 308-318. 